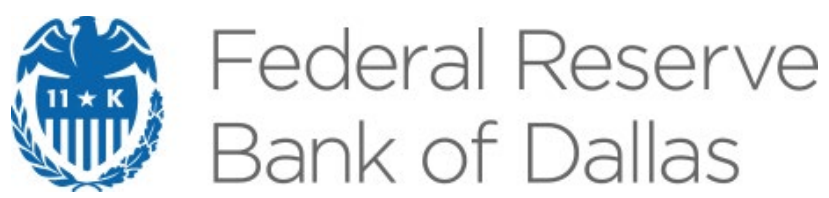

\title{
A Generalized Time Iteration Method for Solving Dynamic Optimization Problems with Occasionally Binding Constraints
}

Ayşe Kabukçuoğlu and Enrique Martínez-García 


\title{
A Generalized Time Iteration Method for Solving Dynamic Optimization Problems with Occasionally Binding Constraints ${ }^{*}$
}

\author{
Ayşe Kabukçuoğlu ${ }^{\dagger}$ and Enrique Martínez-García ${ }^{\ddagger}$ \\ First draft: February 22, 2019 \\ This draft: April 10, 2020
}

\begin{abstract}
We study a generalized version of Coleman (1990)'s time iteration method (GTI) for solving dynamic optimization problems. Our benchmark framework is an irreversible investment model with labor-leisure choice. The GTI algorithm is simple to implement and provides advantages in terms of speed relative to Howard (1960)'s improvement algorithm. A second application on a heterogeneous-agents incomplete-markets model further explores the performance of GTI.
\end{abstract}

JEL Classification: C6, C61, C63, C68.

Keywords: General equilibrium models; Occasionally binding constraints; Computational methods; Time iteration; Policy function iteration; Endogenous grid.

\footnotetext{
*We would like to thank Fabrice Collard for providing invaluable suggestions; Saroj Bhattarai, Jim Dolmas, Umut Dur, Andy Glover, and Zeynep Kabukçuoğlu for helpful comments. We also would like to thank the editor and three anonymous referees for their valuable feedback. The views expressed in this paper are those of the authors and do not necessarily reflect the views of the Federal Reserve Bank of Dallas or the Federal Reserve System.

${ }^{\dagger}$ Ayşe Kabukçuoğlu Dur, North Carolina State University, Department of Economics, 2801 Founders Drive, Raleigh, NC. Email: azkabukc@ncsu.edu. Webpage: http://aysekabukcuoglu.weebly.com.

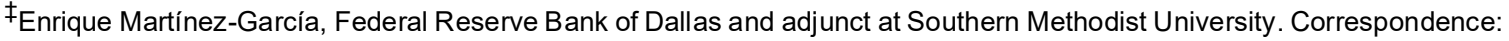
2200 N. Pearl Street, Dallas, TX 75201. Phone: +1 (214) 922-5262. Fax: +1 (214) 922-5194. Email: emg.economics@gmail.com. Webpage: https://sites.google.com/view/emgeconomics/.
} 


\section{Introduction}

Most dynamic models in macroeconomics are in the class of nonlinear rational expectations models, which are complex and rich in structure, and do not exhibit a closed-form, analytical solution. A solution, if it exists, can be obtained only through numerical techniques. A strand of literature has focused on solution methods that use the first order conditions (FOCs) of the optimization problem, such as Judd (1992), Maliar and Maliar (2005), and Maliar et al. (2011). These methods, however, can still be time consuming or rely on the assumption that the decision rules are smooth, which may limit their applicability. Moreover, there may be problems with convergence, depending on the initial guess (see den Haan and Marcet (1990)).

Coleman (1990) and Baxter (1991) suggest methods which explicitly use Euler equations and a grid to approximate the decision rules. This type of approach is particularly useful as it does not rely on the assumption of the smoothness of decision rules. Therefore it can be useful for models with occasionally binding constraints, such as the irreversible investment model or heterogeneous-agents incomplete-markets models in the spirit of Aiyagari (1994). However, speed can be a major concern, as these models can become very sophisticated.

We suggest a method that addresses this issue by generalizing the time iteration method of Coleman (1990), which makes use of policy function iteration on the Euler equation of a simple real business cycle (RBC) model. With time iteration, the aim is to solve a fixed-point equation of the form $c=F(c)$, where $c$ is the optimal policy function and $F$ is derived from the intertemporal Euler equation. This method has been shown to be (theoretically) equivalent to value function iteration (VFI) by Coleman (1990) in an RBC model and in a multidimensional model with occasionally binding constraints by Rendahl (2015).

Our main contribution is to enhance Coleman (1990)'s method to solve dynamic optimization problems with occasionally binding constraints. We call this the generalized time iteration (GTI) method. ${ }^{1}$ In order to explain the implementation more clearly, we start with an RBC model with labor-leisure choice and investment constraints.

In order to solve the problem, we first use Carroll (2006)'s endogenous grid method (EGM). The main idea behind the EGM is to assume that the future endogenous state variable is fixed and the current endogenous state variable is unknown. This is unlike the conventional approach where the current state variable is given and we solve forward to find the optimal state variable tomorrow. ${ }^{2}$

Second, we consider a change of variables in the resource constraint to define a new state variable in this RBC model, which we call "market resources" (i.e. the sum of output and capital after depreciation). This helps solve for current-period capital and labor after convergence is achieved, rather than after every iteration. This dramatically reduces computation time by avoiding a number of extra root-finding procedures. One advantage of using a policy function-based method like ours is that such a switch of state variables is feasible when there are multiple choice variables. ${ }^{3}$ While a more general applicability of Carroll (2006)'s method has been explored in VFI-based techniques, the literature has not focused much on the advantages

\footnotetext{
${ }^{1}$ The MATLAB programs are available here:

http://aysekabukcuoglu.weebly.com/uploads/1/0/1/8/10189079/gti_codes.zip

${ }^{2}$ For instance, in an illustration based on the standard stochastic neoclassical growth model, a solution under EGM involves defining decision rules as a function of next period's capital as opposed to the conventional method that defines them over the current period's capital.

${ }^{3}$ This would not be possible under a VFI based method, as shown by, Barillas and Fernandez-Villaverde (2007) who extends Carroll (2006)'s EGM to include labor-leisure choice.
} 
of policy function iteration (PFI) based techniques. ${ }^{4}$

We compare the speed and accuracy gains from GTI to those of the standard improvement algorithm discussed in Howard (1960). The standard PFI is a high threshold to pass in terms of both speed and accuracy. It makes use of each new computed policy function after considering the value of using that policy forever, usually taking a smaller number of steps for convergence than the standard VFI (See Ljungquist and Sargent (2012) and Santos and Rust (2003)).

While we obtain comparable results on accuracy, significant differences arise in the implementation of GTI and PFI, although both methods are based on fixed-point iteration. In particular, PFI tends to suffer from the curse of dimensionality, whereby GTI provides notable speed advantages. Also, unlike Euler equationbased techniques (such as in den Haan and Marcet (1990)), convergence is achieved under GTI without an educated guess for the policy function of future capital holdings. ${ }^{5}$

Our main illustration of GTI is based on an irreversible investment model with labor-leisure choice, where the additional static choice variable produces more complex solutions and the benefits of the faster GTI solution algorithm are more apparent. ${ }^{6}$ Other useful applications include the potential use of this solution method in workhorse heterogeneous-agent macroeconomic models that allow for incomplete markets. As a more general application, we include a two-country model in the spirit of Aiyagari (1994) and with progressive labor income taxes. This model extends the one in Kabukçuoğlu (2017) by including a labor-leisure choice. The speed and accuracy results of GTI can be seen further in this exercise. An earlier application in a relatively simple Bewley-type economy was studied by Guerrieri and Lorenzoni (2017).

Our final comment pertains to the comparative performance of the GTI in relation to Carroll (2006)'s VFIbased methods. When applying his approach, Carroll (2006) incorporates liquidity constraints in the absence of a labor-leisure choice. Barillas and Fernandez-Villaverde (2007) generalize Carroll (2006)'s endogenous grid point method in an RBC model with a labor-leisure choice (albeit with no inequality constraints) and compare the performance of the generalized EGM against the standard VFI, documenting its advantages in terms of speed. Although the VFI is a natural benchmark in their case, it is not a very difficult benchmark to outperform in terms of speed as the curse of dimensionality is an even more serious problem with VFI. The current work, therefore, also contributes to the literature by documenting the advantages of time iteration, particularly in terms of speed, in the presence of multiple choice variables and occasionally binding constraints - an issue which has not been addressed.

\section{$1.1 \quad$ Related Literature}

There is a vast literature on both local and global solution methods, including perturbation, projection, and value function iteration methods (see, e.g., the literature survey of Fernandez-Villaverde et al. (2016)). A model solution can be obtained with global methods but can also be approximated with perturbation methods (first-order, second-order, or even higher-order perturbations). Martínez-García (2018) provides a general introduction to the first-order perturbation method, while Schmitt-Grohe and Uribe (2004) show

\footnotetext{
${ }^{4}$ Other papers that enhance Carroll (2006)'s EGM based on a value function iteration method include Hintermaier and Koeniger (2010) and Fella (2014) which suggest related solution methods for models with occasionally binding constraints and a decision on durables and non-durables, and White (2015) which considers the theoretical characterization of EGM with multi-dimensional states and controls.

${ }^{5}$ Specifically, this is the policy function for $k^{\prime \prime}$ in our model. Convergence is not guaranteed when applying den Haan and Marcet (1990)'s parameterized expectations approach, even when making use of an educated guess.

${ }^{6}$ See also Rendahl (2015) with an application of irreversible investment with no labor-leisure choice.
} 
how to solve the model using a second-order approximation to the policy function. Andreasen et al. (2018) discuss second- and higher-order approximations and establish the stability of the solution with a pruned state-space system. More directly related to our paper, the perturbation method can also be used in the presence of occasionally binding constraints with the technique of Guerrieri and Iacoviello (2015) (in short, OccBin). Holden (2016) and Holden (2019) develop a more general procedure that improves on OccBin by having some guaranteed convergence properties (if a solution exists) and some extensions to implement higher-order perturbation solutions.

The key advantage of perturbation methods is its tractability and flexibility when the model has a large number of state variables, as shown by Aruoba et al. (2006). However, perturbation methods are local approximations and, therefore, are better suited to approximate the policy function when focusing on small perturbations around the deterministic steady-state. Needless to say, the approximation is less reliable when shocks are large or when the economy appears to be far from the steady-state. A second- or higher-order perturbation method can help approximate the nonlinear features of the policy function (cf., Balke et al. (2017)). Even so, higher-order approximations generally have difficulties handling problems in which the policy function has kinks, such as those that arise from occasionally biding constraints.

Furthermore, the available class of perturbation-based methods depends in general on the existence of a deterministic steady-state in which the constraint always binds, which is not generally a property of the model. Furthermore, with the OccBin method, being under the occasionally binding constraint is like imposing an MIT-type shock because the economy gets there completely unexpectedly and agents act as if the economy will not return to the constraint again in the future. All of these limitations of the different perturbation-based approaches mean that using them imposes some strong constraints on the features of the model under which the policy function can be consistently recovered. The approach proposed in this paper has the advantage of providing a global solution method that overcomes the major limitations of the perturbation method noted here.

Occasionally binding constraints can be better handled with projection methods. For this, the approach consists in projecting the policy function of the model onto some basis functions (Judd (1992)). The basis can be chosen globally (being nonzero and smooth for most of the domain, i.e., the spectral method) or locally (being zero for most of the domain, i.e., the finite-element method). One commonly used basis function is the Chebyshev polynomial, but linear splines can often be a convenient and reliable choice with which to approximate policy functions that have kinks. Christiano and Fisher (2000) instead prefer the use of an adapted version of the parameterized expectations approach (PEA), such as in den Haan and Marcet (1990). This appears to dominate the projection methods (spectral methods but also some finite element methods) on the basis of speed and accuracy, even though convergence cannot be guaranteed when using PEA. Furthermore, the projection methods suffer from the curse of dimensionality. For that reason, Malin et al. (2011), among others, advocate the use of the Smolyak collocation method in order to simplify the computational burden of projections in multidimensional cases.

GTI allows for a flexible computation of the policy function with and without kinks. In the remainder of the paper, we show that this strategy is efficient in terms of time and computational resources. In particular, it maintains accuracy in models with and without kinks when compared to conventional PFI.

The time iteration method we study in this paper is related to the VFI method and closely to the PFI. These methods are popular because they can deal with kinks in policy function as well as with rich economic models (e.g. heterogeneous-agents models). However, the standard applications of these methods are also 
subject to the curse of dimensionality and the choice of grids, in particular, is crucial to determine the computational complexity involved in solving the model. There are several popular methods for choosing the grid points that simplify the computation and can improve the accuracy in recovering the policy function: the quadrature method by Tauchen and Hussey (1991), the randomized grid method by Rust (1997), and the EGM of Carroll (2006) generalized by Barillas and Fernandez-Villaverde (2007).

Our key contribution in this paper is to combine time iteration with the EGM in the presence of occasionally binding constraints. Hence a more efficient algorithm allows us to speed up the computation of the solution, while its accuracy remains comparable to that of conventional PFI.

More recently, the envelope condition method (ECM) by Maliar and Maliar (2013) helps reduce the cost of standard VFI. This approach utilizes the envelope condition as opposed to the first order conditions that are used in standard VFI or EGM. The application of ECM in an RBC model with labor-leisure attains high speed and accuracy results that are comparable to the EGM by Carroll (2006). ${ }^{7}$ In light of this, we did consider experiments with a variant of ECM that iterates over policy functions - a technique which can be more directly compared to GTI. ${ }^{8}$

Accordingly, we find the following results. First, ECM yields highly desirable accuracy and speed results in a model with smooth policy functions. Moreover, higher order polynomials used in policy and value function approximation enhance both the speed and accuracy of ECM. Second, in a model with kinks, the accuracy of ECM deteriorates, as one needs to use different approximation methods to better handle the kinks. We consider this an interesting issue to be addressed in future work.

In the next section, we introduce the GTI method and describe the algorithm for the solution of an RBC model with investment irreversibility. In section 3, we explain the solution under PFI and list the steps of the algorithm. Sections 4 and 5 present the results and compare the performance of these methods under various parameter values, respectively. Section 6 studies an application of GTI in a heterogeneous-agents incomplete-markets framework. In section 7 , we conclude.

\section{The Generalized Time Iteration Method (GTI)}

\subsection{A Real Business Cycle Model with a Constraint on Investment}

Following Christiano and Fisher (2000) and Guerrieri and Iacoviello (2015), we consider a model with a constraint on investment. The expected life-time utility of a representative household is given by

$$
U=\mathbb{E}_{0} \sum_{t=0}^{\infty} \beta^{t}\left[u\left(c_{t}\right)+h\left(1-l_{t}\right)\right]
$$

where $\beta \in(0,1)$ is the discount factor, $c_{t}$ is consumption, and $l_{t} \in[0,1]$ is labor supply (and hence, $1-l_{t}$ is defined as leisure). We assume $u^{\prime}>0, u^{\prime \prime}<0$ and $h^{\prime}<0, h^{\prime \prime}<0$ and both functions are continuously differentiable. ${ }^{9}$ The single aggregate output in the economy, $y_{t}$, is produced using aggregate capital, $k_{t}$, and aggregate labor, $l_{t}$, according to a constant returns to scale production function, $y_{t}=e^{z_{t}} F\left(k_{t}, l_{t}\right)$. The total

\footnotetext{
${ }^{7}$ The mathematical properties and different applications of ECM, including a method that is based on policy function iteration, are studied in Arellano et al. (2016).

${ }^{8}$ These results are not presented in the current paper due to space constraints and are available upon request.

${ }^{9} \mathrm{GTI}$ can only be applied in models with utility functions that are separable in consumption and leisure.
} 
factor productivity (TFP), $z_{t}$, is governed by an $n$-state $(n<\infty)$ first-order Markov process defined with an $n \times n$ transition probability matrix, $\Pi=\left[\pi_{i j}\right]$, where $\pi_{i j}=\operatorname{Pr}\left(z_{t+1}=z_{j} \mid z_{t}=z_{i}\right)$. All elements of $\Pi$ are non-negative and each row sums up to 1 . In any given period, the decisions are made after observing the shock $z_{t}$.

Capital depreciates at rate $\delta \in[0,1]$ in each period. Hence the resource constraint for the social planner's problem can be written as

$$
c_{t}+k_{t+1}=e^{z_{t}} F\left(k_{t}, l_{t}\right)+(1-\delta) k_{t} .
$$

We also have the investment constraint

$$
k_{t+1}-(1-\delta) k_{t} \geq \phi i^{s s}
$$

which encompasses a case with irreversibility under $\phi=0$. Setting $\phi>0$, however, ensures that the constraint is occasionally binding under a standard calibration. The planner's problem is to maximize (1) subject to (2) and (3), the law of motion for TFP shocks, and the initial conditions $k_{0}$ and $z_{0}$.

Equilibrium Conditions. The solution can be characterized by the Kuhn-Tucker conditions,

$$
\begin{aligned}
& u^{\prime}\left(c_{t}\right)-\lambda_{t}=\beta \mathbb{E}_{z_{t+1} \mid z_{t}}\left[u^{\prime}\left(c_{t+1}\right)\left[e^{z_{t+1}} F_{k}\left(k_{t+1}, l_{t+1}\right)+1-\delta\right]-(1-\delta) \lambda_{t+1}\right] \\
& u^{\prime}\left(c_{t}\right) e^{z_{t}} F_{l}\left(k_{t}, l_{t}\right)=h^{\prime}\left(1-l_{t}\right) \\
& c_{t}+k_{t+1}=e^{z_{t}} F\left(k_{t}, l_{t}\right)+(1-\delta) k_{t} \\
& k_{t+1}-(1-\delta) k_{t}-\phi i^{s s} \geq 0 \\
& \lambda_{t} \geq 0 \\
& \left(k_{t+1}-(1-\delta) k_{t}-\phi i^{s s}\right) \lambda_{t} \geq 0
\end{aligned}
$$

and the initial conditions, transversality condition and law of motion for TFP shocks. Notice that the multiplier $\lambda_{t}$ is state-dependent and thus, the investment constraint is occasionally binding.

\subsection{The Generalized Time Iteration (GTI) Method}

In this section, we show how to solve this model based on GTI. This approach requires that we use (4)-(9) to obtain the solutions for consumption, $c_{t}^{*}$, labor, $l_{t}^{*}$, capital, $k_{t}^{*}$, and the multiplier, $\lambda_{t}^{*}$. Hence, GTI follows closely on Coleman (1990)'s time iteration where one considers iteration over policy functions using the optimality conditions.

Furthermore, to enhance speed, we use Carroll (2006)'s EGM and a switch of variables into market resources. This means that instead of defining the grid points over $k_{t}$ and $z_{t}$ and finding $k_{t+1}$ that satisfies (4)-(9), we define the grid points over $k_{t+1}$ and $z_{t}$ to find $k_{t}$, solving the problem algebraically. But in order to avoid solving for $k_{t}$ during every iteration, we redefine variables in terms of market resources, $m_{t}$, and deal with solving for $k_{t}$ only in the final step. Accordingly, the resulting $k_{t}$ values are often off the grid, which is the basic idea of the EGM.

We redefine the endogenous state variable in terms of current period market resources

$$
m_{t}=c_{t}+k_{t+1}
$$


and next period market resources,

$$
m_{t+1}=e^{z_{t+1}} F\left(k_{t+1}, l_{t+1}\right)+(1-\delta) k_{t+1} .
$$

This redefinition enables us to sidestep the burden of using a nonlinear equation solver to find this period's capital and labor in every iteration. Therefore, we only solve for the decision rules for $k_{t}\left(\right.$ and $l_{t}$ ) once, in the final step. This idea was introduced by Carroll (2006) in a model without labor-leisure choice, and such a switch of variables could be feasible under VFI. With the introduction of an additional choice variable, however, this type of a switch is still feasible under GTI but not VFI.

As we consider the transformation into market resources, the time-invariant decision rules we aim to solve for are $c_{t}^{*}=\tilde{g}_{c}\left(m_{t}^{*}, z_{t}\right), l_{t}^{*}=\tilde{g}_{l}\left(m_{t}^{*}, z_{t}\right), k_{t+1}^{*}=\tilde{g}_{k}\left(m_{t}^{*}, z_{t}\right)$, and $\lambda_{t}^{*}=\tilde{g}_{\lambda}\left(m_{t}^{*}, z_{t}\right)$, which will eventually help us find the actual functions $c_{t}^{*}=g_{c}\left(k_{t}^{*}, z_{t}\right), l_{t}^{*}=g_{l}\left(k_{t}^{*}, z_{t}\right), k_{t+1}^{*}=g_{k}\left(k_{t}^{*}, z_{t}\right)$, and $\lambda_{t}^{*}=g_{\lambda}\left(k_{t}^{*}, z_{t}\right)$ using (4)-(9) .

We start with an initial guess for two functions, $k_{t+2}=\tilde{g}_{k}\left(m_{t+1}, z_{t+1}\right)=g_{k}\left(k_{t+1}, z_{t+1}\right)$ and $\lambda_{t+1}=$ $\tilde{g}_{\lambda}\left(m_{t+1}, z_{t+1}\right)=g_{\lambda}\left(k_{t+1}, z_{t+1}\right)$. Notice that $m_{t+1}$ takes values as a function of the points over the grid for $k_{t+1}$, which implies that we base our guess on the grid points of $k_{t+1}$.

With the initial guess for $k_{t+2}=g_{k}\left(k_{t+1}, z_{t+1}\right)$, we can solve for $l_{t+1}$ using Newton's method by combining (5), (6), and (7) as:

$$
\max \left\{k_{t+2},(1-\delta) k_{t+1}+\phi i^{s s}\right\}-e^{z_{t+1}} F\left(k_{t+1}, l_{t+1}\right)-(1-\delta) k_{t+1}+u^{\prime}-1\left[\frac{h^{\prime}\left(1-l_{t+1}\right)}{e^{z_{t+1}} F_{l}\left(k_{t+1}, l_{t+1}\right)}\right]=0 .
$$

Notice that since $k_{t+2}=g_{k}\left(k_{t+1}, z_{t+1}\right)$, equation (12) is defined over $\left(k_{t+1}, z_{t+1}\right)$ gridpoints. Therefore, a solution for next period's labor is also defined over values of $\left(k_{t+1}, z_{t+1}\right)$, i.e. $l_{t+1}=g_{l}\left(k_{t+1}, z_{t+1}\right)$. We can construct (6) in terms of the next period's market resources $m_{t+1}$, and pin down next period's consumption,

$$
c_{t+1}=m_{t+1}-\max \left\{k_{t+2},(1-\delta) k_{t+1}+\phi i^{s s}\right\} .
$$

Next, we find current period consumption from (4), assuming the investment constraint (7) is slack, and therefore $\lambda_{t}=0$. As the utility function is separable in consumption and leisure, and using the initial guess for $\lambda_{t+1}$ and the functions $c_{t+1}, l_{t+1}$ we found earlier, we can solve for $c_{t}$ directly from the Euler equation,

$$
c_{t}=u^{\prime-1}\left[\beta \mathbb{E}_{z_{t+1} \mid z_{t}} u^{\prime}\left[g_{c}\left(k_{t+1}, z_{t+1}\right)\right]\left[e^{z_{t+1}} F_{k}\left(k_{t+1}, g_{l}\left(k_{t+1}, z_{t+1}\right)\right)+1-\delta\right]-(1-\delta) \lambda_{t+1}\right] .
$$

Then, it is easy to compute current period market resources $m_{t}$ from (10).

We then consider the case where $\lambda_{t} \geq 0$ and (7) is binding. Using (4), the policy functions $c_{t+1}, l_{t+1}$, the initial guess for $\lambda_{t+1}$, and the grid points for $k_{t+1}$ and $z_{t+1}$, we obtain:

$$
\lambda_{t}=u^{\prime}\left(c_{b i n d}\right)-\beta \mathbb{E}_{z_{t+1} \mid z_{t}}\left[u^{\prime}\left(c_{t+1}\right)\left[e^{z_{t+1}} F_{k}\left(k_{t+1}, l_{t+1}\right)+1-\delta\right]-(1-\delta) \lambda_{t+1}\right]
$$

where $c_{b i n d}$, defined over $\left(k_{t+1}, z_{t}\right)$, is the current period consumption when the investment constraint is binding. To find $c_{b i n d}$, we first find the current-period capital $k_{b i n d}$ that solves

$$
k_{t+1}-(1-\delta) k_{\text {bind }}-\phi i^{s s}=0 .
$$


We are then able to find $c_{b i n d}, l_{b i n d}$ jointly from equations (5) and (6) over values of $\left(k_{t+1}, z_{t}\right)$. Notice that $k_{b i n d}, c_{b i n d}$, and $l_{b i n d}$ can be found outside of the iterative cycle, with exact solutions over grid points when constraint (7) is binding.

Our guess for $k_{t+2}$ and $\lambda_{t+1}$ is then updated without finding $k_{t}$ or $l_{t}$ and only using market resources, $m_{t}$. The main idea is that we can consider $k_{t+1}$ a time-invariant function of $m_{t}$ and $z_{t}$, i.e. $k_{t+1}=\tilde{g}_{k}\left(m_{t}, z_{t}\right)$. This implies that both $k_{t+2}$ and $\lambda_{t+1}$ can be expressed as a function of next period's states, $\left(m_{t+1}, z_{t+1}\right)$. We can then interpolate both $k_{t+2}$ and $\lambda_{t+1}$ on $m_{t+1}$ using $m_{t}$ and $z_{t}$ (using piecewise cubic hermite interpolating polynomials). With the resulting values for $k_{t+2}$ and $\lambda_{t+1}$, we update our guess until a stopping criterion is satisfied. Once convergence is achieved with a solution, $c_{t}$, we can find $l_{t}$ and $k_{t}$ jointly from (5) and (6) with Christopher Sim's csolve.m routine.

In the final step, we need to find the actual policy functions. We find $k_{t}^{*}=\min \left(k_{t}, k_{b i n d}\right)$. Then, we recover $c_{t}^{*}$ and $l_{t}^{*}$ using values of $k_{t}^{*}, k_{t+1}$, and $z_{t}$ from $(5)-(6)$ where we make use of Christopher Sim's csolve.m routine once again. The actual $\lambda_{t}^{*}$ can be found similarly, using (15) from the final iteration. Below we describe the GTI algorithm in further detail.

\subsection{The GTI Algorithm}

Define the grid points for future capital, $\mathcal{G}_{k} \equiv\left\{k_{1}, k_{2}, \ldots, k_{M}\right\}$, and use the Rouwenhorst (1995) approximation method to obtain the discretized stochastic process for the total factor productivity shocks, defined with grid points $\mathcal{G}_{z_{t}} \equiv\left\{z_{1}, z_{2}, \ldots, z_{N}\right\}$ with the associated transition probability matrix. The steps of the algorithm are given as follows:

1. Find the exact solutions for $k_{b i n d}$ from (7). Find $c_{b i n d}$ and $l_{\text {bind }}$ jointly from (5) and (6) over values of $\left(k_{t+1}, z_{t}\right) \in \mathcal{G}_{k_{t+1}} \times \mathcal{G}_{z_{t}}$ using Christopher Sim's csolve.m.

2. Set $i=0$ and make a policy function guess $k_{t+2}^{i}=\tilde{g}_{k}^{i}\left(m_{t+1}, z_{t+1}\right)=g_{k}^{i}\left(k_{t+1}, z_{t+1}\right)$. We start with a guess that sets $k_{t+2}^{i}=\left(k^{s s}\right)^{\alpha}\left(l^{s s}\right)^{1-\alpha}$ for all state pairs $\left(k_{t+1}, z_{t+1}\right) \in \mathcal{G}_{k_{t+1}} \times \mathcal{G}_{z_{t}}$. Make a guess for the multiplier such that $\lambda_{t+1}^{i}=\tilde{g}_{\lambda}^{i}\left(m_{t+1}, z_{t+1}\right)=g_{\lambda}^{i}\left(k_{t+1}, z_{t+1}\right)=0$ for all $\left(k_{t+1}, z_{t+1}\right) \in \mathcal{G}_{k_{t+1}} \times \mathcal{G}_{z_{t}}$ and initialize the current period market resources $m_{t}^{i}\left(k_{t+1}, z_{t}\right)=0$ for all $\left(k_{t+1}, z_{t}\right) \in \mathcal{G}_{k_{t+1}} \times \mathcal{G}_{z_{t}}$.

3. For each point of $k_{t+2}^{i}$ and associated state $\left(k_{t+1}, z_{t+1}\right) \in \mathcal{G}_{k_{t+1}} \times \mathcal{G}_{z_{t}}$, solve the nonlinear equation for $l_{t+1}$ and $c_{t+1}$ using Newton's method jointly from (5)-(7) (which is quite fast). ${ }^{10}$ Then find $c_{t}$ from (4) over the grid points $\left(k_{t+1}, z_{t}\right)$ using (4) for the case $\lambda_{t}=0$. Using these decision rules, compute the current and next period's market resources $m_{t}^{i+1}$ and $m_{t+1}^{i+1}$, respectively. Then compute $\lambda_{t}$ by treating it as a residual in (4), with $c_{t}=c_{b i n d}$.

4. Check if $\sup _{m, n}\left|m_{t}^{i+1}\left(k_{m}, z_{n}\right)-m_{t}^{i}\left(k_{m}, z_{n}\right)\right| \geq 1.0 e^{-6}$. If convergence is not achieved, let $i \rightsquigarrow i+1$ and $m_{t}^{i+1}=m_{t}^{i}$. Update the decision rule for capital using interpolation. In particular, we use piecewise cubic hermite interpolating polynomials ('pchip' in MATLAB) to interpolate $\tilde{g}_{k}^{i+1}\left(m_{t+1}, z_{t+1}\right)$ on $m_{t+1}^{i+1}$ using $m_{t}^{i+1}{ }^{11}$ Conduct another interpolation step for $\tilde{g}_{\lambda}^{i}\left(m_{t+1}, z_{t+1}\right)$. Go to step 2.

\footnotetext{
${ }^{10}$ Other alternatives for MATLAB such as fsolve and csolve (by Christopher Sims) appear to yield the same results but require more computation time.

${ }^{11}$ Different interpolation techniques are studied in detail in Judd (1998) pp. 216-235.
} 
5. If convergence is achieved, use $c_{t}$ to find $l_{t}$ and $k_{t}$ jointly from (5) and (6) with a nonlinear equation solver. Here, we use Christopher Sim's csolve.m function in MATLAB. The resulting values from this step can be used to find the actual policy function $k_{t}^{*}=\min \left(k_{t}, k_{b i n d}\right)$ given $\left(k_{t+1}, z_{t}\right)$. The states $k_{t}^{*}$, $k_{t+1}$, and $z_{t}$ enable us to find actual values for $c_{t}^{*}$ and $l_{t}^{*}$ from equations (5) and (6). Hence we find the solution to the problem, $c_{t}=g_{c}\left(k_{t}^{*}, z_{t}\right), l_{t}=g_{l}\left(k_{t}^{*}, z_{t}\right)$, and $k_{t+1}=g_{k}\left(k_{t}^{*}, z_{t}\right)$.

\section{Policy Function Iteration (PFI)}

The standard PFI is known to be a very powerful method for solving this class of models (see, e.g., Ljungquist and Sargent (2012), pp. 106-107) as it provides convergence at a quadratic rate rather than a linear rate, as in the case of value function iteration (Puterman and Brumelle (1979) and Santos and Rust (2003)). It is also a natural benchmark for us since GTI relies on policy function iteration. In this section we will describe how the current model with a labor-leisure choice can be solved with the PFI method. In order to iterate on a policy function, we need to express the problem in recursive form.

Defining $k_{t+1}$ as our control variable and treating the intratemporal FOC (5) as an additional constraint, we plug in (5) and (6) for $l_{t}$ and $c_{t}$ and express the period utility function for all values of $z_{t}, k_{t}$, and $k_{t+1}$. We thus define the dynamic programming problem as follows:

$$
V\left(k_{t}, z_{t}\right)=\max _{\substack{k_{t+1} \\ \text { s.t. } k_{t+1} \geq(1-\delta) k_{t}+\phi i^{s s}}}\left\{u\left(z_{t}, k_{t}, k_{t+1}\right)+h\left(z_{t}, k_{t}, k_{t+1}\right)+\beta \mathbb{E}_{z_{t+1} \mid z_{t}} V\left(k_{t+1}, z_{t+1}\right)\right\} .
$$

This problem can also be solved by defining the control variables as $k_{t+1}$ and $l_{t}$ and using additional grids for labor. However, the method performs poorly in terms of speed and accuracy and turns out to be a weaker benchmark to compare against GTI.

We then pick a feasible policy function, $k_{t+1}=g_{k}^{i}\left(k_{t}, z_{t}\right)$, and compute the value associated with the infinite horizon problem using this policy,

$$
V_{i}\left(g_{k}^{i}\left(k_{t}, z_{t}\right), z_{t+1}\right)=\mathbb{E}_{0} \sum_{t=0}^{\infty} \beta^{t} u\left(k_{t}, g_{k}^{i}\left(k_{t}, z_{t}\right)\right),
$$

with $i=0$. Next, we consider the policy improvement step, where the policy function solves:

$$
\tilde{g}_{k}^{i+1}\left(k_{t}, z_{t}\right)=\arg \max _{k_{t+1}}\left\{u\left(z_{t}, k_{t}, k_{t+1}\right)+h\left(z_{t}, k_{t}, k_{t+1}\right)+\beta \mathbb{E}_{z_{t+1} \mid z_{t}} V_{i}\left(g_{k}^{i}\left(k_{t}, z_{t}\right), z_{t+1}\right)\right\}
$$

to find the actual policy function,

$$
g_{k}^{i+1}\left(k_{t}, z_{t}\right)=\max \left[\tilde{g}_{k}^{i+1}\left(k_{t}, z_{t}\right),(1-\delta) k_{t}+\phi i^{s s}\right]
$$

and the associated value function. Notice that this policy function $g_{k}^{i+1}\left(k_{t}, z_{t}\right)$ lies off the grids when the constraint is binding, so we pick the nearest gridpoint $k_{t+1}$ for the resulting policy function. Then iterate over $i$ until convergence is obtained for steps (17) and (18). 


\subsection{The PFI Algorithm}

We define the (current-period) grid points for capital, $\mathcal{G}_{k} \equiv\left\{k_{1}, k_{2}, \ldots, k_{M}\right\}$, and use the Rouwenhorst (1995) approximation method to obtain the discretized stochastic process for the total factor productivity shocks, defined with grid points $\mathcal{G}_{z_{t}} \equiv\left\{z_{1}, z_{2}, \ldots, z_{N}\right\}$ with the associated transition probability matrix. The steps of the algorithm are described as follows:

1. For each triplet of productivity shock, today's and tomorrow's capital $\left(z_{t}, k_{t}, k_{t+1}\right) \in \mathcal{G}_{k} \times \mathcal{G}_{k} \times \mathcal{G}_{z}$, we construct the matrix $u\left(z_{t}, k_{t}, k_{t+1}\right)+h\left(z_{t}, k_{t}, k_{t+1}\right)$. To do this, we solve the nonlinear equation resulting from (5) and (6) for $l_{t}$ using Newton's method and find $c_{t}$ using (6), over the grid points $\left(k_{t}, z_{t}\right) .{ }^{12}$

2. Set $i=0$ and construct the initial value function $V_{i}\left(k_{t}, z_{t}\right)$. In order for this to be consistent with the initial guess in GTI, we set $V_{i}\left(k_{t}, z_{t}\right)=u\left(c^{s s}\right)+h\left(1-l^{s s}\right)$ for all $\left(z_{t}, k_{t}, k_{t+1}\right) \in \mathcal{G}_{k} \times \mathcal{G}_{k} \times \mathcal{G}_{z}$.

3. We find the decision rule $g_{k}^{i+1}\left(k_{t}, z_{t}\right)=\arg \max \left\{u\left(z_{t}, k_{t}, k_{t+1}\right)+h\left(z_{t}, k_{t}, k_{t+1}\right)+\beta \mathbb{E}_{z_{t+1} \mid z_{t}} V_{i}\left(g_{k}^{i}\left(k_{t}, z_{t}\right), z_{t+1}\right)\right\}$.

4. We then need to compute the value of using this policy forever and solve forward the Bellman equation in (18) to find the new value function $V_{i+1}$.

5. Check if $\sup _{m, n}\left|V_{i+1}\left(k_{m}, z_{n}\right)-V_{i}\left(k_{m}, z_{n}\right)\right| \geq 1.0 e^{-6}$. If convergence is not achieved, go to step 2 and let $i \rightsquigarrow i+1$.

6. If convergence is achieved, find $l_{t}=g_{l}\left(k_{t}, z_{t}\right)$ using Newton's method and $c_{t}=g_{c}\left(k_{t}, z_{t}\right)$ from the resource constraint.

Even though the construction of $u\left(z_{t}, k_{t}, k_{t+1}\right)$ in step 1 of PFI is done only once, it requires the use of a numerical solver $N_{k} \times N_{k} \times N_{z}$ times. In GTI however, this procedure is repeated $N_{k} \times N_{z}$ times, for each iteration when obtaining the labor decision rules in step 2. It requires a quantitative exercise to find out which method is more time-consuming in this step. Our numerical experiments reveal that we need a sufficiently large $N_{k}$ to obtain more accurate results with PFI, and, in that case PFI is clearly slower than GTI. The rest of the speed advantages in GTI can be attributed to the time-convention in the grid points and the redefinition of the state variable in terms of market resources.

\section{Parameterization and Numerical Findings}

Let the intertemporal discount factor be $\beta=0.9896$ and the instantaneous utility function be given by $u(c)=\theta \ln c, h(1-l)=(1-\theta) \ln (1-l)$ where $\theta=0.357$. This produces a steady-state value for labor of 0.31 . We let $F(k, l)=k^{\alpha} l^{1-\alpha}$, where $\alpha=0.4$. Capital's depreciation rate is $\delta=0.0196$. Following Guerrieri and Iacoviello (2015), the parameterization of $\phi=0.975$ implies that the investment constraint is binding about $40 \%$ of the time. The TFP shock process takes the form $z_{t}=\rho z_{t-1}+\varepsilon_{t}$, where $\varepsilon_{t} \sim N\left(0, \sigma^{2}\right)$. The first-order autocorrelation is set at $\rho=0.95$ and the volatility at $\sigma=0.007$. The TFP process is discretized into nine states, as in Rouwenhorst (1995).

We follow the standard procedure in the literature (cf. Judd (1992) and Barillas and Fernandez-Villaverde (2007)) to assess the accuracy of our solutions and calculate the normalized intertemporal Euler equation

\footnotetext{
${ }^{12}$ Christopher Sim's csolve function in MATLAB provides the same results at the expense of greater computation time.
} 
errors (denoted by EE) implied by the decision rules. The maximum and mean Euler equation errors from the simulation of the model are reported for 10,000 periods. The results are obtained with MATLAB version R2018a on a PC with Intel(R) Core(TM) i7-7700 CPU $3.60 \mathrm{GHz}(3.60 \mathrm{GHz})$. We use linearly-spaced grids and consider the performance of both methods under a range of different number of grid points with $k_{1}=0.3 k^{s s}$ and $k_{M}=1.8 k^{s s}$, where $k^{s s}$ is the steady-state level of capital. Identical grids are used when comparing the two methods. Baseline calibration yields $k^{s s}=23.1$ and $i^{s s}=0.45$.

As shown in Table 1, the main advantage of the GTI algorithm is its speed. The accuracy remains robust across all grid sizes as GTI involves mostly algebraic operations and nonlinear solvers. When the number of nodes is 500, convergence is achieved in 345 iterations and $28.8 \mathrm{CPU}$ seconds. The mean and maximum intertemporal Euler equation errors (EE) are -3.78 and -3.31 , respectively (in log 10 units). For PFI, the other results seem rather mixed. The method produces relatively large maximum Euler equation errors, but this is in part because, for comparability, the solution is found on an identical and linearly-spaced grid which may be too coarse to accurately describe the policy function (particularly so in the presence of kinks in the policy function). Accuracy improvements require finer grid points, which comes at higher time costs. In general, GTI dominates PFI mostly in terms of speed.

\begin{tabular}{l|rccc}
\hline \hline \multicolumn{5}{c}{ Table 1: Results } \\
\hline \multicolumn{5}{c}{ GTI } \\
\hline Grid points & CPU time & Mean EE error & Max EE error & Iterations \\
10 & $2.4 s$ & -3.72 & -3.29 & 342 \\
500 & $28.8 s$ & -3.78 & -3.31 & 345 \\
1,000 & $57.0 s$ & -3.78 & -3.38 & 345 \\
2,000 & $1 m 47.5 s$ & -3.79 & -3.29 & 345 \\
\hline \multicolumn{5}{c}{ PFI } \\
\hline 10 & $.1 s$ & -2.80 & -2.53 & 2 \\
500 & $3 m 28.5 s$ & -3.59 & -1.22 & 11 \\
1,000 & $26 m 4 s$ & -3.85 & -1.43 & 11 \\
2,000 & $3 h 35 m 13.3 s$ & -3.98 & -1.40 & 11 \\
\hline
\end{tabular}

Note: We report the mean and maximum of absolute Euler equation errors (in $\log 10$ units). Errors are obtained from a stochastic simulation of 10,000 periods.

The GTI algorithm requires more iterations for convergence. However, the total time spent for the solution of the problem shows that each iteration is completed faster compared to the time spent for each iteration in PFI. The speed in GTI can be attributed to (i) the time convention of grid points such that the grids are defined in terms of tomorrow's capital rather than today's capital, and (ii) that the solution of capital and labor for the current period is made only once, and only at the end of the algorithm when convergence is achieved. Figures 4-5 in the appendix plot the policy functions for GTI and PFI, respectively.

In addition to the simulation results under the benchmark parameterization presented in Table 1, it is possible to see the range of Euler equation errors in Figure 1, where we depict the intertemporal Euler equation errors (in $\log 10$ units) for each method over 500 capital grid points and nine productivity shock nodes. 

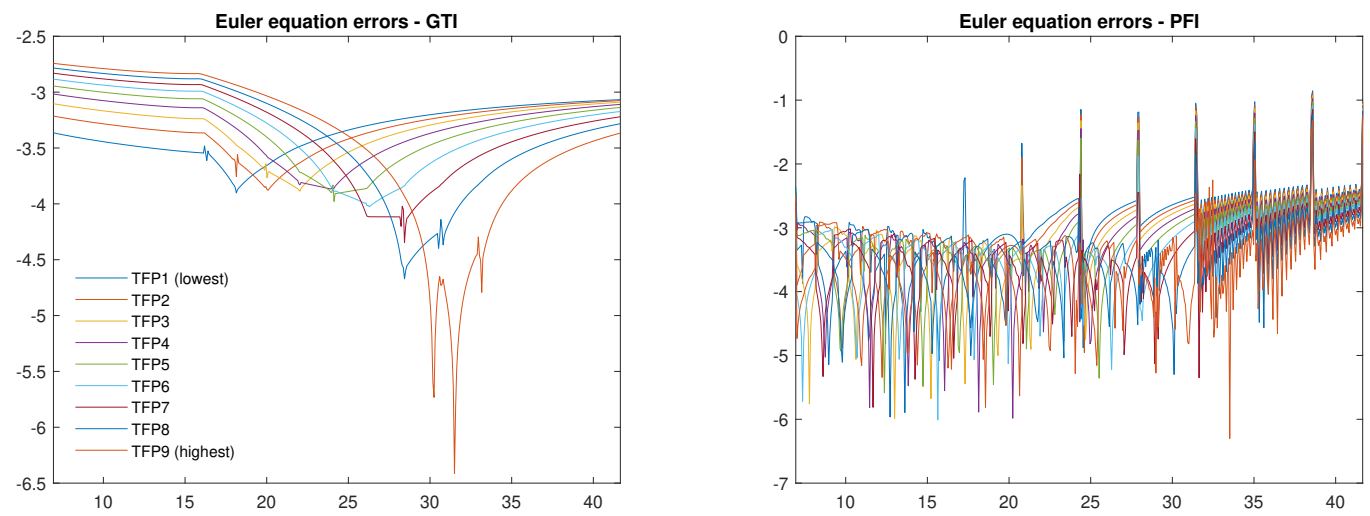

Figure 1: Intertemporal Euler equation errors (in log 10 units) from 500 capital grid points and nine productivity nodes under the benchmark calibration.

\section{Robustness Analysis}

Here we compare GTI and PFI under different scenarios. The baseline scenario considers the benchmark parameterization as described above. In the remaining scenarios, we change one parameter at a time and keep all other parameters at their baseline values. All experiments consider 500 grid points for capital and nine grid points for the productivity shock. Table 2 (Table 3) summarizes the results for GTI (PFI).

\begin{tabular}{lcccc}
\hline \hline \multicolumn{5}{c}{ Table 2: Robustness analysis for GTI } \\
\hline \multicolumn{5}{c}{$500 x 9$ grid points } \\
\hline bxperiments & CPU time & Mean EE1 error & Max EE error & Iterations \\
$\beta=0.96$ & $28.8 s$ & -3.78 & -3.31 & 345 \\
$\beta=0.99$ & $15.4 s$ & -3.51 & -2.91 & 161 \\
$\rho=0.99$ & $29.2 s$ & -3.79 & -3.30 & 351 \\
$\rho=0.90$ & $28.3 s$ & -3.69 & -2.94 & 338 \\
$\sigma=0.013$ & $28.8 s$ & -3.85 & -3.49 & 351 \\
$\alpha=0.3$ & $27.2 s$ & -3.55 & -3.05 & 327 \\
$\alpha=0.5$ & $28.8 s$ & -3.63 & -3.07 & 287 \\
$\phi=0$ & $50.1 s$ & -3.97 & -3.48 & 386 \\
$\phi=1$ & $23.1 s$ & -3.19 & -2.96 & 603 \\
\hline
\end{tabular}

Note: We report the mean and maximum of absolute Euler equation errors (in $\log 10$ units). Errors are obtained from a stochastic simulation of 10,000 periods.

These results confirm that the major advantage of GTI appears to be speed, as can be seen from various experiments. GTI helps compute non-smooth decision rules more accurately than PFI. In particular, in scenarios where the constraint is more likely to bind (e.g. $\phi=1$ ), GTI yields more accurate results. 


\begin{tabular}{lcccc}
\hline \hline \multicolumn{5}{c}{ Table 3: Robustness analysis for PFI } \\
\hline \multicolumn{5}{c}{ 500x9 grid points } \\
\hline Experiments & CPU time & Mean EE error & Max EE error & Iterations \\
baseline & $3 m 28.5 s$ & -3.59 & -1.22 & 11 \\
$\beta=0.96$ & $3 m 5.8 s$ & -3.66 & -1.58 & 10 \\
$\beta=0.99$ & $3 m 14.1 s$ & -3.56 & -1.32 & 11 \\
$\rho=0.99$ & $6 m 50.6 s$ & -3.48 & -1.17 & 24 \\
$\rho=0.90$ & $2 m 59.4 s$ & -3.15 & -2.70 & 10 \\
$\sigma=0.013$ & $3 m 46.7 s$ & -3.55 & -1.10 & 13 \\
$\alpha=0.3$ & $3 m 22.7 s$ & -3.49 & -1.26 & 11 \\
$\alpha=0.5$ & $3 m 5.5 s$ & -3.36 & -1.27 & 11 \\
$\phi=0$ & $4 m 16.3 s$ & -3.65 & -3.02 & 15 \\
$\phi=1$ & $3 m 17.2 s$ & -3.16 & -1.37 & 11 \\
\hline
\end{tabular}

Note: We report the mean and maximum of absolute Euler equation errors (in $\log 10$ units). Errors are obtained from a stochastic simulation of 10,000 periods.

\section{Application: A Two-Country Heterogeneous-Agents Incomplete- Markets Model with Progressive Taxes}

In this section, we consider an application of the GTI method to a richer framework: a two-country heterogeneous-agents incomplete-markets model with flat-rate capital gains taxes, progressive labor income taxes, and government debt. The model can be useful for studying several questions, including topics of financial globalization and wealth inequality (e.g. Mendoza et al. (2007) and Mendoza et al. (2009)) or redistributive effects of taxation (including the work of Domeij and Heathcote (2004) and Heathcote et al. (2017), among many others).

At the core of the model lies an Aiyagari (1994)-type production economy with uninsured idiosyncratic labor income risk and borrowing constraints. In considering a role for government and the open-economy aspects, the model comes closest to the one in Kabukçuoğlu (2017), which studies the redistributive effects of tax reform in a similar framework. We extend the model of Kabukçuoğlu (2017) to include households' labor-leisure choice, applying the GTI method to recover households' decision rules. Following Aiyagari (1994) and Judd et al. (2017), the equilibrium interest rate is found using the bisection method.

\subsection{The Model}

The world economy consists of two countries, Country 1 and Country 2. For convenience, we present the model for a given country, suppressing the country index $i$. Throughout this, household variables are denoted by lowercase letters whereas country-level (aggregate) variables are denoted by uppercase letters. 


\subsubsection{Households}

In each country, households are subject to labor efficiency (or productivity) shocks, $\varepsilon_{t} \in E$ which are i.i.d. across households and persistent over time. This is the only uncertainty in the model. In any given period, households make decisions upon the realization of their productivity shock. Household productivity $\varepsilon_{t}$ is assumed to follow a Markov process captured by an $m \times m$ transition probability matrix $\Pi=\left[\pi_{i j}\right]$, where $\pi_{i j}=\operatorname{Pr}\left(\varepsilon_{t+1}=\varepsilon_{j} \mid \varepsilon_{t}=\varepsilon_{i}\right)$. The probability distribution over $E$ is given by $p_{t} \in \mathbb{R}^{m}$. Given an initial distribution $p_{0}$, the period-t distribution is given by $p_{t}=p_{0} \Pi^{t}$.

Households' preferences are given by:

$$
E_{0}\left[\sum_{t=0}^{\infty} \beta^{t}\left[u\left(c_{t}\right)-g\left(n_{t}\right)\right]\right]
$$

where $u$ is a strictly increasing and concave function of $c_{t}$ and $g$ is a strictly increasing and convex function of $n_{t}$. Both functions are also continuously differentiable. The discount rate is $\beta \in(0,1)$. In each period, a household's consumption is denoted by $c_{t}$ and hours worked are denoted by $n_{t}$. We assume identical preferences and labor income processes for both countries.

A households' budget constraint can be written as:

$$
c_{t}+\underbrace{b_{t+1}+d_{t+1}+k_{t+1}}_{\equiv a_{t+1}} \leq \tau^{n}\left(\varepsilon_{t} n_{t} w_{t}\right)^{\psi}+\underbrace{\left[1+\left(r_{t}^{k}-\delta\right)\left(1-\tau^{k}\right)\right] k_{t}+\left[1+r_{t}^{d}\left(1-\tau^{k}\right)\right] d_{t}+\left(1+r_{t}\right) b_{t}}_{\equiv\left(1+r_{t}\right) a_{t}} .
$$

Accordingly, a household spends on consumption goods $c_{t}$ and invest in assets, $a_{t+1}$. Following Kabukçuoğlu (2017), we define three assets with a one-period, risk-free, real return: private bonds $b_{t+1}$, which pays the world interest rate $r_{t}$, government bonds $d_{t+1}$ with an interest rate $r_{t}^{d}$, and capital goods $k_{t+1}$ with a rental rate $r_{t}^{k}$. Capital depreciates at a rate $\delta \in[0,1]$. The only internationally traded asset is the private bond. A household's pre-tax labor income is given by $\varepsilon_{t} n_{t} w_{t}$, where $w_{t}$ is the wage rate. Households' after-tax labor income is given by $\tau^{n}\left(\varepsilon_{t} n_{t} w_{t}\right)^{1-\psi}$ with a two-parameter progressive labor income tax function as in Heathcote et al. (2017). This tax function in general can be written as $\tau(y)=y-\tau^{n} y^{1-\psi}$ where $y=\varepsilon n w$ denotes pre-tax labor earnings, and $\psi$ is a progressivity measure of the tax system (e.g. $\psi=0$ implies a flat-rate tax). The second parameter, $\tau^{n}$, is associated with the average taxation of labor income. The tax on capital income is assumed to be flat rate, $\tau^{k} \in[0,1]$, implying an after-tax return of $\left(r_{t}^{k}-\delta\right)\left(1-\tau^{k}\right)$. The government bonds are taxed at the same rate as capital and their net return is given by $r_{t}^{d}\left(1-\tau^{k}\right)$. Both countries have an identical tax system, while the values of tax parameters may differ. ${ }^{13}$ We abstract from taxes on internationally traded bonds in the current framework.

The no-arbitrage condition is given by:

$$
r_{t}=r_{t}^{d}\left(1-\tau^{k}\right)=\left(r_{t}^{k}-\delta\right)\left(1-\tau^{k}\right)
$$

\footnotetext{
${ }^{13}$ See Kabukçuoğlu (2017) for a discussion on the possibility of cross-country differences in taxation in a two-country model and the underlying assumptions needed for this result.
} 
where $r_{t}$ is the world interest rate, common to both countries. Given that households are indifferent as to which asset to purchase in equilibrium, it is possible to state the household's problem without considering the portfolio composition of assets. The budget constraint can be written as:

$$
c_{t}+a_{t+1} \leq \tau^{n}\left(\varepsilon_{t} n_{t} w_{t}\right)^{1-\psi}+\left(1+r_{t}\right) a_{t} .
$$

Households are also borrowing constrained, determined by an exogenous borrowing limit, a:

$$
a_{t} \geq \underline{a} .
$$

The possibility of having a series of low productivity shocks and the presence of the borrowing limit induces a precautionary savings motive, as in the Aiyagari (1994) framework. It is possible to consider economies with no net borrowing, $\underline{a}=0$, in which case any short position in an asset, e.g. private bonds, must be matched with a long position of the same amount in another asset, e.g. government debt.

For the household problem, there are two state variables $\left(a_{t}, \varepsilon_{t}\right)$, at any period $t$. Notice that each household's consumption, saving, or labor-leisure decisions throughout their lifetime are heterogeneous and depend on the history of the idiosyncratic shocks and their initial conditions $\left(a_{0}, \varepsilon_{0}\right)$. The dynamic optimization problem is described as follows. Given the deterministic sequences of prices $\left\{w_{t}, r_{t}^{k}, r_{t}^{d}, r_{t}\right\}_{\tau=0}^{\infty}$, government policy $\left\{\tau(\cdot), \tau^{k}\right\}$, and initial conditions $\left(a_{0}, \varepsilon_{0}\right)$, a household in a given country chooses $a_{t+1}, c_{t}$, and $n_{t}$ to maximize (20), subject to (22) and (23).

\subsubsection{Firms}

In each country, output $Y_{t}$ is produced by a representative firm using aggregate capital $K_{t}$ and labor $N_{t}$ according to a constant returns to scale production function, $Y_{t}=F\left(K_{t}, N_{t}\right)$. Taking prices $\left(w_{t}, r_{t}^{k}\right)$ as given, the firm's problem in each country is to maximize profits:

$$
F\left(K_{t}, N_{t}\right)-r_{t}^{k} K_{t}-w_{t} N_{t},
$$

by choosing factors both of which are internationally immobile. Perfectly competitive factor markets lead to zero profits in equilibrium.

\subsubsection{Governments}

Governments can raise revenues by issuing bonds, $D_{t+1}$, locally at an interest rate, $r_{t}^{d}$, and collecting taxes from households to finance a constant amount of government expenditures, $G$. The assumption of no international mobility of government bonds allows us to pin down the aggregate amount of private bonds $\left(B_{t}\right)$ and public bonds $\left(D_{t}\right)$ in equilibrium. We denote the aggregate tax revenues from progressive labor income taxes $\tau(\cdot)$ by $T R_{t}$. With taxes on capital income and, given an initial government bonds $D_{0}$, the period government budget constraint can be written as:

$$
G+r_{t}^{d} D_{t}=D_{t+1}-D_{t}+T R_{t}+K_{t}\left(r_{t}^{k}-\delta\right) \tau^{k}+D_{t} r_{t}^{d} \tau^{k}
$$




\subsection{Equilibrium Characterization and Solution}

Define $A$ as the set of all possible (household) endogenous states, $A=[\underline{a}, \infty]$. Consider $(A, \mathcal{A})$ and $(E, \mathcal{E})$ the measurable spaces where $\mathcal{A}$ denotes the Borel set that is the set of all subsets of $A$ and $\mathcal{E}$ is the set of all subsets of $E$. Then let $(S, \mathcal{S})=(A \times E, \mathcal{A} \times \mathcal{E})$ be the product space where $S$ is the set of all possible household states. The solution to the household's problem in Country 1 (and similarly in Country 2) provides the decision rules for consumption, $c_{t}=c\left(a_{t}, \varepsilon_{t}\right)$, labor $n_{t}=n\left(a_{t}, \varepsilon_{t}\right)$ and asset holdings, $a_{t+1}=s\left(a_{t}, \varepsilon_{t}\right)$ given the initial conditions $\left(a_{0}, \varepsilon_{0}\right)$ and the history of shocks summarized by $\varepsilon^{t}$. These rules determine the evolution of the distribution of agents over $\left(a_{t}, \varepsilon_{t}\right)$. The joint (endogenous) distribution of households across wealth and labor efficiency is given by $\mu_{t}=\mu\left(a_{t}, \varepsilon_{t}\right)$. A household with the state $\left(a_{t}, \varepsilon_{t}\right)$ will have a state vector in the set $A_{t+1} \times E_{t+1}$ next period, given the current distribution and the decision rules. Starting with an initial distribution $\mu\left(a_{0}, \varepsilon_{0}\right)$, households' distribution across wealth and productivity levels evolves according to:

$$
\mu\left(a_{t+1}, \varepsilon_{t+1}\right)=\sum_{\varepsilon_{t+1} \in E} \Pi\left(\varepsilon_{t+1} \mid \varepsilon_{t}\right) \mu\left(a_{t}, \varepsilon_{t}\right)
$$

A general equilibrium under financial integration is characterized by the following conditions:

1. Household Euler equationL

$$
u_{c}\left(c_{t}^{i}\right)=\beta E_{\varepsilon_{t+1} \mid \varepsilon_{t}}\left(1+r_{t+1}\right)\left[u_{c}\left(c_{t+1}^{i}\right)+\tilde{\lambda}_{t+1}^{i}\right]
$$

2. Household borrowing constraints, with the associated multiplier, $\tilde{\lambda}_{t}^{i}$ :

$$
a_{t} \geq \underline{a}^{i}
$$

3. Household intratemporal FOC:

$$
u_{c}\left(c_{t}^{i}\right) \tau^{\prime}\left(\varepsilon_{t} n_{t}^{i} w_{t}^{i}\right) \varepsilon_{t} w_{t}^{i}=u_{n}\left(n_{t}^{i}\right)
$$

4. Aggregations:

$$
\int_{(a, \varepsilon)} c_{t}^{i} d \mu_{t}^{i}=C_{t}^{i}, \int_{(a, \varepsilon)} n_{t}^{i} \varepsilon_{t} d \mu_{t}^{i}=N_{t}^{i}, \int_{(a, \varepsilon)} a_{t+1}^{i} d \mu_{t}^{i}=A_{t+1}^{i}
$$

5. Firm optimization and factor prices:

$$
\begin{aligned}
r_{t}^{k i} & =F_{K}\left(K_{t}^{i}, N_{t}^{i}\right), \\
w_{t}^{i} & =F_{N}\left(K_{t}^{i}, N_{t}^{i}\right),
\end{aligned}
$$


6. Asset market clearing condition:

$$
A_{t}^{1}+A_{t}^{2}=K_{t}^{1}+K_{t}^{2}+D_{t}^{1}+D_{t}^{2}
$$

7. Government budget constraint:

$$
G^{i}+r_{t}^{d i} D_{t}^{i}=D_{t+1}^{i}-D_{t}^{i}+T R_{t}^{i}+K_{t}^{i}\left(r_{t}^{k i}-\delta\right) \tau^{k i}+D_{t}^{i} r_{t}^{d i} \tau^{k i}
$$

8. No-arbitrage:

$$
\left(r_{t}^{k i}-\delta\right)\left(1-\tau^{k i}\right)=F_{K}\left(K_{t}^{i}, N_{t}^{i}\right)\left(1-\tau^{k i}\right)=r_{t} .
$$

for all $t$. The sequence of distributions $\left\{\mu_{t}^{i}\right\}_{t=1}^{\infty}$ is consistent with the initial distributions $\mu_{0}^{i}$, individual policies and idiosyncratic shocks as given by (26) and initial asset holding positions, $A_{0}^{i}, D_{0}^{i}$, $K_{0}^{i}$ for all countries $i=1,2$.

In addition, it is possible to define investment $I_{t} \equiv K_{t+1}-(1-\delta) K_{t}$, net foreign assets $B_{t} \equiv A_{t}-K_{t}-D_{t}$, current account, $C A_{t} \equiv B_{t+1}-B_{t}$, net exports, $N X_{t} \equiv B_{t+1}-B_{t}\left(1+r_{t}\right)$, and net factor payments, $N F P_{t} \equiv r_{t} B_{t}$, based on these aggregates.

\subsection{Calibration and Numerical Solution}

Focusing on the steady-state equilibrium, the solution of the problem involves two steps (i) an algorithm that solves for the equilibrium prices and aggregate variables and (ii) the solution for households' decision rules. The solution steps are explained in the appendix.

We use 6,000 equally spaced asset grid points for policy functions and 120,000 asset grid points for ergodic distributions. The asset grid has a minimum value of -2 and a maximum value of 200 .

Preferences and technology: We specify preferences as $u\left(c_{t}\right)=\frac{c_{t}^{1-\gamma}}{1-\gamma}, g\left(n_{t}\right)=B \frac{n_{t}^{1+1 / \eta}}{1+1 / \eta}$, and technology as $Y_{t}=F\left(K_{t}, N_{t}\right)=Z K_{t}^{\alpha} N_{t}^{1-\alpha}$. We let $\gamma=2$ and $\eta=0.5$ following Domeij and Flodén (2006). We set $B=60$, which yields an average hours worked of $32 \%$ and $27 \%$ of the time endowment in each country, respectively. For the rest of the model, our calibration strategy is in line with Kabukçuoğlu (2017), where Country 1 and Country 2's parameters aim to match the US and rest of the OECD data (subject to availability), respectively. Capital's share $\alpha$ is set as 0.36 , and the depreciation rate $\delta$ is 0.06 for both countries. The discount rate $\beta$ is 0.971 . Each country has a unit mass of population. We normalize the TFP parameter $Z^{2}=1$ and set $Z^{1}=0.6$ to generate a realistic GDP share for the US, which is $34 \%$ in the model.

Borrowing limits: For each country we set $\underline{a}=0$. 
Labor earnings process: We consider a three-state Markov process, following the parameterization of Domeij and Heathcote (2004). We set $E=\left\{\varepsilon^{h}, \varepsilon^{m}, \varepsilon^{l}\right\}$ with $\varepsilon^{h}=4.74, \varepsilon^{m}=0.847$, and $\varepsilon^{l}=0.170$, in both countries. The transition probabilities are given by:

$$
\Pi=\left[\begin{array}{ccc}
\Pi_{11} & 1-\Pi_{11} & 0 \\
\frac{1-\Pi_{22}}{2} & \Pi_{22} & \frac{1-\Pi_{22}}{2} \\
0 & \Pi_{11} & 1-\Pi_{11}
\end{array}\right]=\left[\begin{array}{ccc}
0.90 & 0.10 & 0 \\
0.005 & 0.99 & 0.005 \\
0 & 0.10 & 0.90
\end{array}\right] .
$$

The implied stationary probability distribution is $p^{*}=\left[\begin{array}{lll}0.0455 & 0.9091 & 0.0455\end{array}\right]$.

Government policy: The progressivity parameters are $\psi^{1}=\psi^{2}=0.151$. We set labor and capital income taxes, $\tau^{n 1}=0.73, \tau^{n 2}=0.67, \tau^{k 1}=0.397$, and $\tau^{k 1}=0.425$, respectively. Initial public debt-to GDP ratios $D_{0}^{1} / Y_{0}^{1}$ and $D_{0}^{2} / Y_{0}^{2}$ are 0.70 and 0.94 , respectively. The steady-state government budget constraint implies that the government spending is determined by the calibration of the level of public debt.

\subsection{Results}

Steady-state equilibrium prices, allocations, and wealth distributions: The calibration of the model results in a steady-state equilibrium world interest rate of $2.51 \%$, with capital-to-GDP ratios of 3.54 (Country 1) and 3.47 (Country 2). The wage rates are given as 0.59 and 1.29 , respectively. The resulting government spending to GDP ratios are $51.4 \%$ (Country 1) and $73.6 \%$ (Country 2). Aggregate tax revenues are $47.3 \%$ (Country 1) and $68 \%$ (Country 2) of GDP. Finally, we obtain trade balances that are $-1.69 \%$ and $0.81 \%$ of the GDP, respectively, which are not targeted by any of the model parameters. The Gini coefficients for wealth are 0.56 in both countries. The policy functions for asset holdings are defined as current period (endogenous) asset holdings over next period's asset grids (and productivity levels) due to the use of endogeneous gridpoints. In a final step, we use linear interpolation to switch to a more conventional definition of policy functions and find next period's asset holdings over (currently defined) asset grid points. While this is not necessary for computing the equilibrium, it is considered here for presentation purposes. Figure 2 plots these policy functions.

GTI performance: We report the maximum and mean intertemporal Euler equation errors from a simulation of 10,000 periods conducted for each country. For the current model, the Euler equation errors are computed for the cases where a household's borrowing constraint is not binding. Accordingly, the CPU time for the computation of steady-steady state equilibrium is $43 \mathrm{~m}$. $37.5 \mathrm{~s}$., where policy functions and ergodic distributions are computed several times for each country. The computation of the equilibrium is achived in 148 iterations, spending approximately 17.6 seconds on average per iteration. The bisection method is known to be sensitive to the choice of the initial guess on the real interest rate and thus the total computation time varies significantly. In the two-country model, the initial guess on the (world) real interest rate lies between the autarky interest rates of the respective economies, which is below $1 / \beta-1$. The unit-free (absolute) mean and maximum Euler equation errors are very close for the two countries, -3.79 and -1.61 (in $\log 10$ units), respectively. Figure 3 plots the intertemporal Euler equation errors (in $\log 10$ units) across 6,000 asset grid points and three productivity shock nodes. 

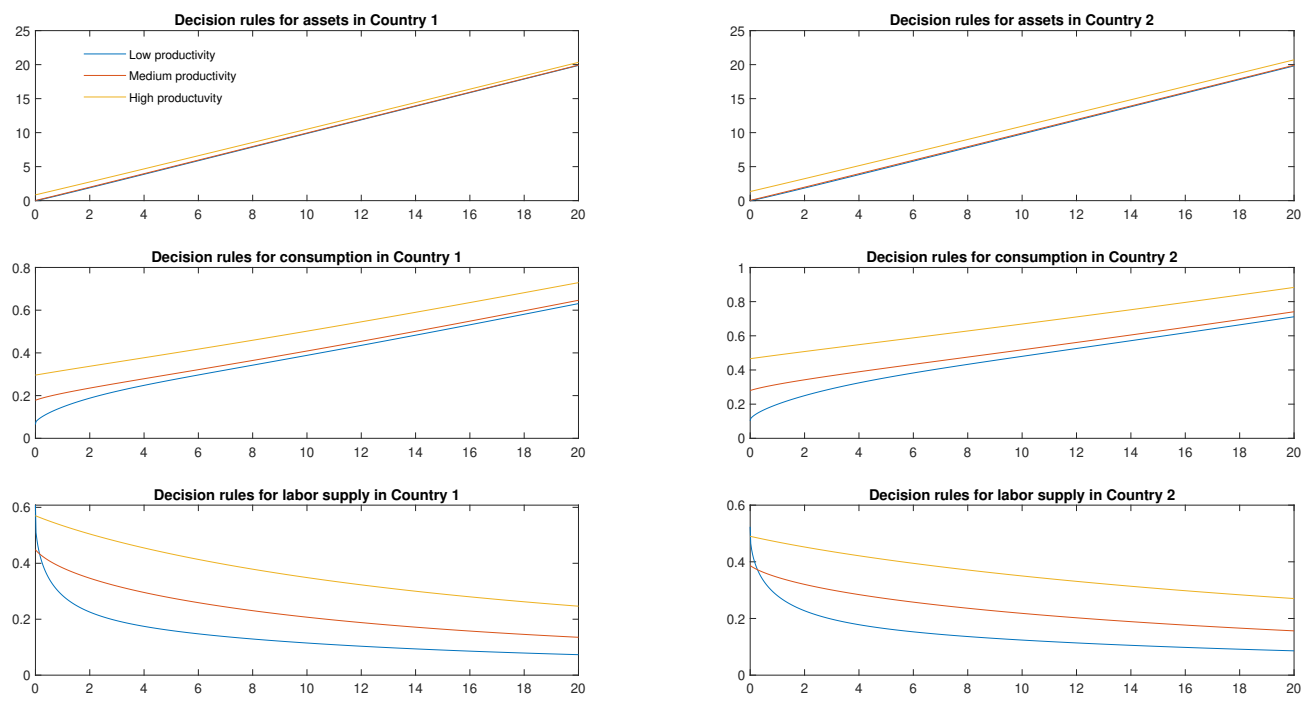

Figure 2: Decision rules for the two-country heterogeneous-agents incomplete-markets model computed using three productivity shock nodes, 6,000 grid points for decision rules, and 120,000 grid points for asset distributions.
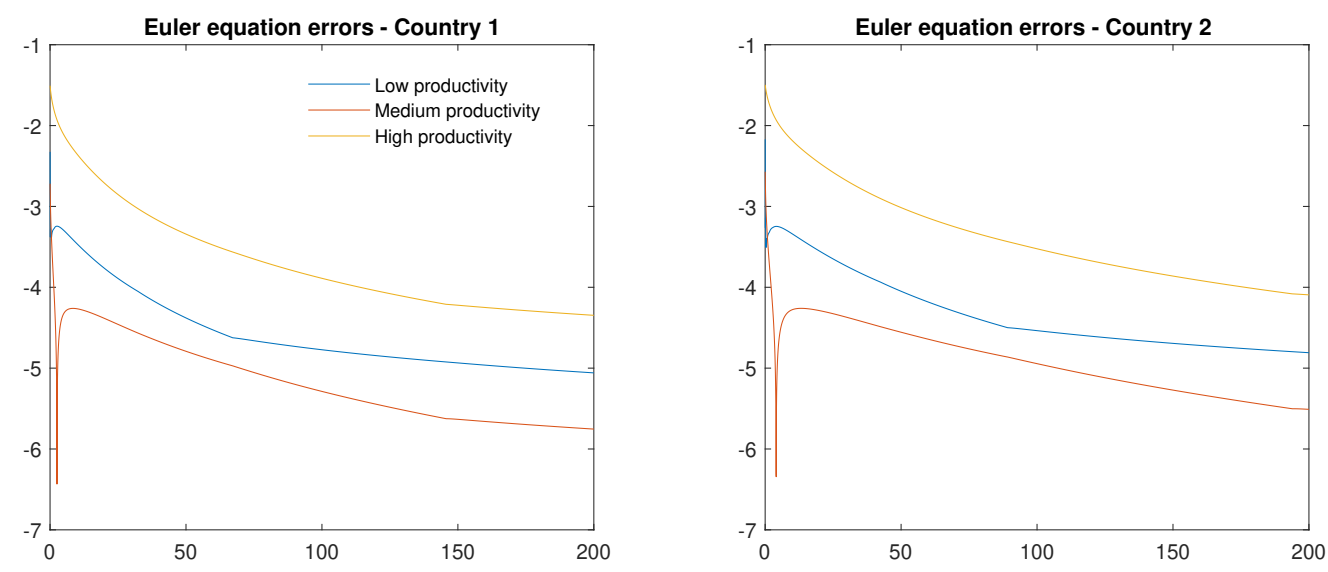

Figure 3: Unit-free absolute intertemporal Euler equation errors (in log 10 units) from 6,000 asset grid points and three productivity nodes for each country. 


\section{Conclusion}

The presence of multiple control variables in a dynamic programming problem may complicate the procedure that is used to find a global solution, which may affect its computational time and/or accuracy. Such cases arise in models where there is an endogenous labor-leisure choice in the well-known irreversible investment model. In this paper, we evaluate a generalized version of time iteration (GTI) and show that it yields similar accuracy results to the standard policy function iteration (PFI) and outperforms the PFI method in terms of speed. The applicability and performance of GTI are further illustrated in a richer heterogeneous-agents incomplete-markets model. 


\section{References}

[1] Aiyagari, S. R. (1994): Uninsured Idiosyncratic Risk and Aggregate Saving, Quarterly Journal of Economics, 109, 659-84. https://doi.org/10.2307/2118417

[2] Andreasen, M. M., J. Fernandez-Villaverde, and J. F. Rubio-Ramirez (2018): The Pruned State-Space System for Non-Linear DSGE Models: Theory and Empirical Applications, The Review of Economic Studies, 85, 1-49. https:/ / doi.org/10.1093/restud/rdx037

[3] Arellano, C., L. Maliar, S. Maliar, and V. Tsyrennikov (2016): Envelope Condition Method with an Application to Default Risk Models, Journal of Economic Dynamics and Control, 69, 436-459. https://doi.org/10.1016/j.jedc.2016.05.016

[4] Aruoba, S. B., J. Fernandez-Villaverde, and J. F. Rubio-Ramirez (2006): Comparing Solution Methods for Dynamic Equilibrium Economies, Journal of Economic Dynamics and Control, 30, 2477-2508. https://doi.org/10.1016/j.jedc.2005.07.008

[5] Balke, N., E. Martínez-García, and Z. Zeng (2017): Understanding the Aggregate Effects of Credit Frictions and Uncertainty, Federal Reserve Bank of Dallas Globalization and Monetary Policy Institute Working Paper No. 317, june 2017 (Revised: October 2019). https:/ / doi.org/10.24149/gwp317r1

[6] Barillas, F. and J. Fernandez-Villaverde (2007): A Generalization of the Endogenous Grid Method, Journal of Economic Dynamics and Control, 31, 2698-2712. https://doi.org/10.1016/j.jedc.2006.08.005

[7] Baxter, M. (1991): Approximating Suboptimal Dynamic Equilibria: An Euler Equation Approach, Journal of Monetary Economics, 28, 173-200. https:/ / doi.org/10.1016/0304-3932(91)90049-t

[8] Carroll, C. D. (2006): The Method of Endogenous Grid for Solving Dynamic Optimization Problems, Economics Letters, 91, 312-320. https://doi.org/10.1016/j.econlet.2005.09.013

[9] Christiano, L. and J. D. Fisher (2000): Algorithms for Solving Dynamic Models with Occasionally Binding Constraints, Journal of Economic Dynamics and Control, 24, 1179-1232. https://doi.org/10.1016/s0165-1889(99)00016-0

[10] Coleman, W. J. (1990): Solving the Stochastic Growth Model by Policy Function Iteration, Journal of Business and Economic Statistics, 8, 27-29. https://doi.org/10.1080/07350015.1990.10509769

[11] den Haan, W. J. and A. Marcet (1990): Solving the Stochastic Growth Model by Parameterizing Expectations, Journal of Business and Economic Statistics, 8, 31-34. https:/ / doi.org/10.1080/07350015.1990.10509770

[12] Domeij, D. and M. Flodén (2006): The Labor-Supply Elasticity and Borrowing Constraints: Why Estimates are Biased, Review of Economic Dynamics, 9, 242-262. https://doi.org/10.1016/j.red.2005.11.001

[13] Domeij, D. and J. Heathcote (2004): On The Distributional Effects Of Reducing Capital Taxes, International Economic Review, 45, 523-554. https:/ / doi.org/10.1111/j.1468-2354.2004.00135.x

[14] Fella, G. (2014): A Generalized Endogenous Grid Method for Non-Smooth and Non-Concave Problems, Review of Economic Dynamics, 17, 329-344. https:/ / doi.org/10.1016/j.red.2013.07.001

[15] Fernandez-Villaverde, J., J. F. Rubio-Ramirez, and F. Schorfheide (2016): Solution and Estimation Methods for DSGE Models, in Handbook of Macroeconomics, ed. by J. B. Taylor and 
H. Uhlig, Amsterdam, The Netherlands: North Holland, Elsevier, vol. 2A, chap. 9, 527-724. https://doi.org/10.1016/bs.hesmac.2016.03.006

[16] Guerrieri, L. and M. Iacoviello (2015): OccBin: A Toolkit for Solving Dynamic Models with Occasionally Binding Constraints Easily, Journal of Monetary Economics, 70, 22-38. https://doi.org/10.1016/j.jmoneco.2014.08.005

[17] Guerrieri, V. and G. Lorenzoni (2017): Credit Crisis, Precautionary Savings, and the Liquidity Trap, Quarterly Journal of Economics, 132, 1427-1467. https://doi.org/10.1093/qje/qjx005

[18] Heathcote, J., K. Storesletten, and G. L. Violante (2017): Optimal Tax Progressivity: An Analytical Framework, Quarterly Journal of Economics, 132, 1693-1754. https://doi.org/10.1093/qje/qjx018

[19] Hintermaier, T. and W. Koeniger (2010): The Method of Endogenous Gridpoints with Occasionally Binding Constraints among Endogenous Variables, Journal of Economic Dynamics and Control, 34, 2074-2088. https://doi.org/10.1016/j.jedc.2010.05.002

[20] Holden, T. D. (2016): Computation of Solutions to Dynamic Models with Occasionally Binding Constraints, EconStor Preprints 144569, ZBW - Leibniz Information Centre for Economics. https://www.econstor.eu/bitstream/10419/144569/1/ComputationalPaper_rev.pdf

[21] Holden, T. D. (2019): Existence and Uniqueness of Solutions to Dynamic Models with Occasionally Binding Constraints, EconStor Preprints 144570, ZBW - Leibniz Information Centre for Economics. https:/ / www.econstor.eu/bitstream/10419/204472/1/TheoryPaperBody.pdf

[22] Howard, R. A. (1960): Dynamic Programming and Markov Processes, Cambridge, MA: MIT Press.

[23] Judd, K. L. (1992): Projection Methods for Solving Aggregate Growth Models, Journal of Economic Theory, 58, 410-452. https://doi.org/10.1016/0022-0531(92)90061-1

[24] Judd, K. L. (1998): Numerical Methods in Economics, Cambridge, MA: MIT Press.

[25] Judd, K. L., L. Maliar, S. Maliar, and I. Tsener (2017): How to Solve Dynamic Stochastic Models Computing Expectations Just Once, Quantitative Economics, 8, 851-893. https://doi.org/10.3982/QE329

[26] Kabukçuoğlu, A. (2017): The Winners and Losers of Tax Reform: An Assessment under Financial Integration, Journal of Economic Dynamics and Control, 85, 90-122. https://doi.org/10.1016/j.jedc.2017.09.009

[27] Ljungquist, L. and T. Sargent (2012): Recursive Macroeconomic Theory, MIT Press.

[28] Maliar, L. and S. Maliar (2005): Parameterized Expectations Algorithm: How to Solve for Labor Easily, Computational Economics, 25, 269-274. https://doi.org/10.1007/s10614-005-2224-9

[29] Maliar, L. and S. Maliar (2013): Envelope Condition Method versus Endogenous Grid Method for Solving Dynamic Programming Problems, Economics Letters, 120, 262-266. https://doi.org/10.1016/j.econlet.2013.04.031

[30] Maliar, S., L. Maliar, and K. L. Judd (2011): Solving the Multi-Country Real Business Cycle Model Using Ergodic Set Methods, Journal of Economic Dynamics and Control, 35, 207-228. https://doi.org/10.1016/j.jedc.2010.09.014 
[31] Malin, B. A., D. Krueger, and F. Kubler (2011): Solving the Multi-Country Real Business Cycle Model Using a Smolyak-Collocation Method, Journal of Economic Dynamics and Control, 35, 229-239. https://doi.org/10.1016/j.jedc.2010.09.015

[32] Martínez-García, E. (2018): Finite-Order VAR Representation of Linear Rational Expectations Models: With Some Lessons for Monetary Policy, Federal Reserve Bank of Dallas, Globalization and Monetary Policy Institute Working Paper no. 285, september 2016 (Revised: August 2018). https://doi.org/10.24149/gwp285r2

[33] Mendoza, E., V. Quadrini, and J. V. Rios-Rull (2007): On the Welfare Implications of Financial Globalization without Financial Development, NBER Working Paper no: 13412. https://www.nber.org/papers/w13412

[34] Mendoza, E. G., V. Quadrini, and J.-V. Rios-Rull (2009): Financial Integration, Financial Development, and Global Imbalances, Journal of Political Economy, 117, 371-416. http://dx.doi.org/10.1086/599706

[35] Puterman, M. L. and S. L. Brumelle (1979): On the Convergence of Policy Iteration in Stationary Dynamic Programming, Mathematics of Operations Research, 4, 60-69. https://www.jstor.org/stable/3689678

[36] Rendahl, P. (2015): Inequality Constraints and Euler Equation-Based Solution Methods, The Economic Journal, 125, 1110-1135. https:/ /doi.org/10.1111/ecoj.12115

[37] Rouwenhorst, K. G. (1995): Asset Pricing Implications of Equilibrium Business Cycle Models, in Frontiers of Business Cycle Research, ed. by T. F. Cooley, Princeton University Press, Princeton, NJ, chap. 10, 294-330.

[38] Rust, J. (1997): Using Randomization to Break the Curse of Dimensionality, Econometrica, 65, 487-516. http://doi.org/10.2307/2171751

[39] Santos, M. S. and J. Rust (2003): Convergence Properties of Policy Iteration, SIAM Journal on Control and Optimization, 42, 2094-2115.

[40] Schmitt-Grohe, S. and M. Uribe (2004): Solving Dynamic General Equilibrium Models Using a SecondOrder Approximation to the Policy Function, Journal of Economic Dynamics and Control, 28, 755775. https://doi.org/10.1016/S0165-1889(03)00043-5

[41] Tauchen, G. and R. Hussey (1991): Quadrature-Based Methods for Obtaining Approximate Solutions to Nonlinear Asset Pricing Models, Econometrica, 59, 317-396. http:/ / doi.org/10.2307/2938261

[42] White, M. N. (2015): The Method of Endogenous Gridpoints in Theory and Practice, Journal of Economic Dynamics and Control, 60, 26-41. https://doi.org/10.1016/j.jedc.2015.08.001 


\section{Appendix}

\subsection{Figures}
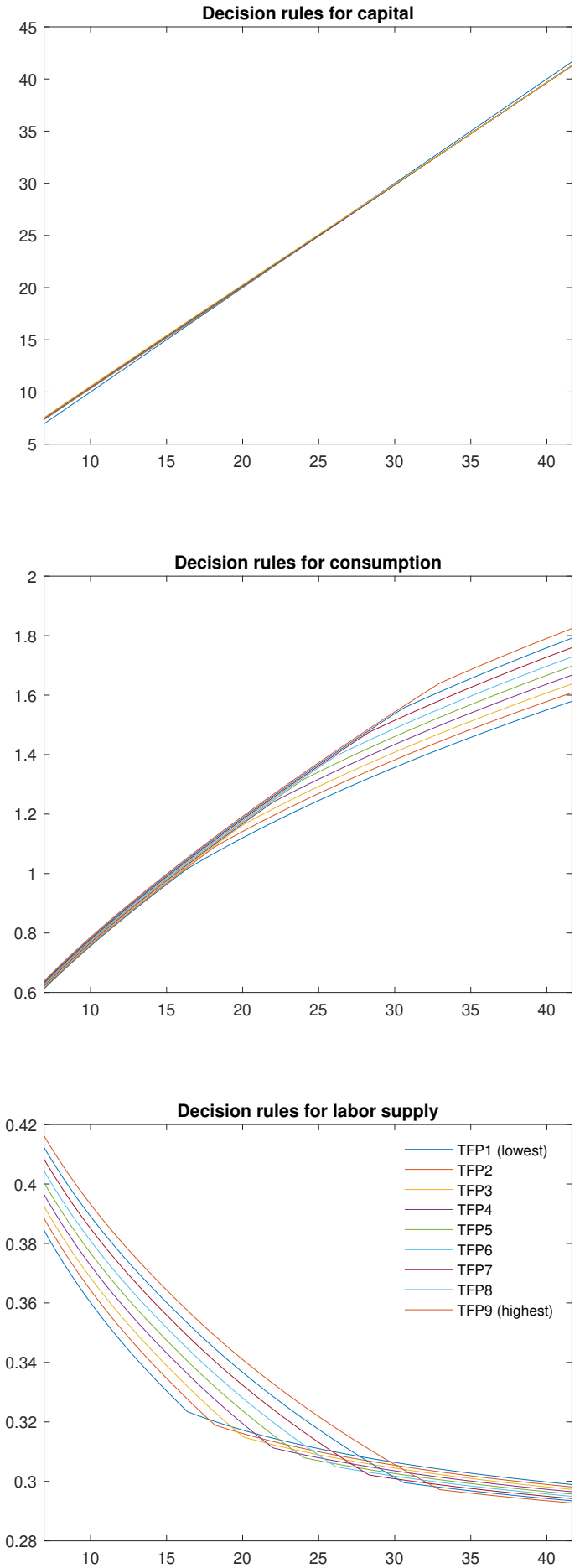

Figure 4: Decision rules obtained under GTI with 500 capital grid points and 9 productivity nodes. 

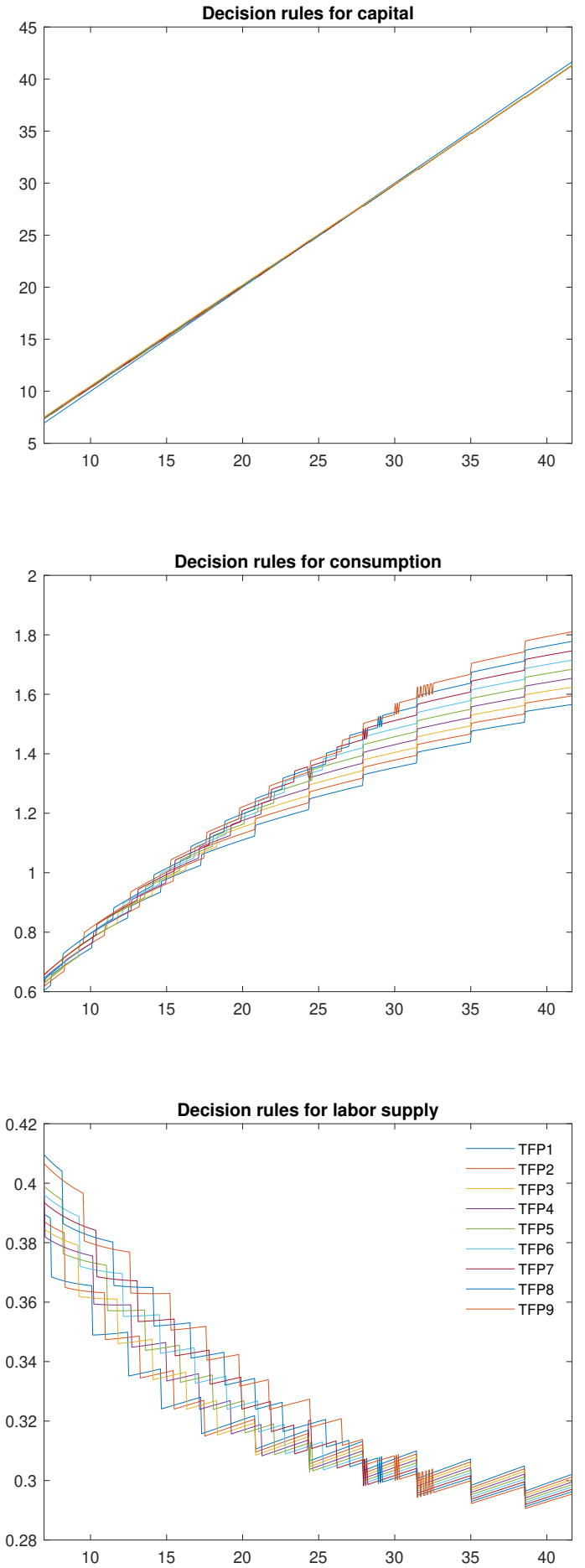

Figure 5: Decision rules obtained under PFI with 500 capital grid points and 9 productivity nodes. 


\subsection{Solving the Heterogeneous-Agents Incomplete-Markets Model with GTI}

For each country, generate grid points on next period's assets and current period shocks, $\left(a^{\prime}, \varepsilon\right)$, where $a^{\prime} \epsilon A=\left\{a_{1}, a_{2}, \ldots, a_{N}\right\}$. The borrowing limit can be selected slightly above $a_{1}$. The borrowing limit is occasionally binding while the upper limit of asset grid points $a_{N}$ never binds. Define $\varepsilon \in E=\left\{\varepsilon_{1}, \ldots, \varepsilon_{M}\right\}$.

1. The interest rate is to be found based on the bisection method where we start with a guess on $r$, where $r \in(0,1 / \beta-1)$. Also set values for $D_{0}$ and $D_{0}^{*}$. From the no-arbitrage condition (35), compute the implied $K / N$ ratio and the remaining factor prices for both countries: $r^{k 1}, r^{k 2}, w^{1}$, and $w^{2}$.

2. Initialize the cumulative distributions of households over assets and shocks, $\Gamma_{0}\left(a^{\prime}, \varepsilon\right)$ for each country.

3. Initialize next period's consumption policy functions, $c_{0}\left(a^{\prime}, \varepsilon^{\prime}\right)$ and do steps $4-9$ for each country.

4. Assuming that the constraint is not binding, construct the right-hand side of the Euler equation for all pairs of $\left(a^{\prime}, \varepsilon^{\prime}\right) \epsilon A \times E$, and solve for current-period consumption function $\tilde{c}$,

$$
U_{c}(\tilde{c})=\beta(1+r) \sum_{\varepsilon^{\prime} \in E} \Pi\left(\varepsilon^{\prime} \mid \varepsilon\right) U_{c}\left(c_{0}\left(a^{\prime}, \varepsilon^{\prime}\right)\right) .
$$

5. Given $\tilde{c}$, using the intratemporal FOC (29), solve for $\tilde{n}\left(a^{\prime}, \varepsilon\right)$. The utility function in our example yields an easy computation of the household labor supply, while in other cases the Newton method be needed.

6. Using the budget constraint, compute current asset holdings $\tilde{a}\left(a^{\prime}, \varepsilon\right)$ such that:

$$
\tilde{a}\left(a^{\prime}, \varepsilon\right)=\left[\tilde{c}+a^{\prime}-\tau^{n}(\tilde{n} w \varepsilon)^{\psi}\right] /(1+r) .
$$

Hence, we find current assets given next period asset holdings is $a^{\prime}$ and today's productivity shock is $\varepsilon$. Again, the current state $\tilde{a}\left(a^{\prime}, \varepsilon\right)$ is not necessarily on the grids defined in $A$. We then consider two cases:

a. If $\tilde{a}\left(a^{\prime}, \varepsilon\right)$ causes the borrowing constraint to bind next period, we compute $\tilde{c}_{0}\left(a^{\prime}, \varepsilon\right)$ using piecewise linear interpolation on the closest grid points $a_{i}$ and $a_{j}$ such that, $a_{i}<\bar{a}\left(a^{\prime}, \varepsilon\right)<a_{j}$ and using consumption rules at $c_{0}\left(a_{i}, \varepsilon\right)$ and $c_{0}\left(a_{j}, \varepsilon\right)$. The corresponding labor supply values can be computed from $(29)$.

b. If $\tilde{a}\left(a^{\prime}, \varepsilon\right)$ causes the borrowing constraint not to bind next period, then set $\tilde{c}_{0}\left(a^{\prime}, \varepsilon\right)=\tilde{c}$ from step 6 .

7. Check convergence for a small value of $\epsilon$, based on the metric:

$$
\max \left\{\left|\tilde{c}_{0}\left(a^{\prime}, \varepsilon\right)-c_{0}\left(a^{\prime}, \varepsilon\right)\right|\right\}<\epsilon .
$$

Iterate using steps $4-6$ until convergence.

8. Given the initial guess for distributions, $\Gamma_{0}\left(a^{\prime}, \varepsilon\right)$, interpolate on grid points $a_{i}$ and $a_{j}$ to find the distribution over the endogenous grid points, $\left.\Gamma\left(s^{-1}\left(a^{\prime}, \varepsilon\right)\right), \varepsilon\right)$ using the endogenous grids $\tilde{a}\left(a^{\prime}, \varepsilon\right)$. Then update the distribution using: 


$$
\tilde{\Gamma}\left(a^{\prime}, \varepsilon^{\prime}\right)=\sum_{\varepsilon} \Pi\left(\varepsilon^{\prime} \mid \varepsilon\right) \Gamma_{0}\left(\bar{a}\left(a^{\prime}, \varepsilon\right), \varepsilon\right),
$$

and iterate until convergence.

9. Compute aggregate savings, labor, capital and the output level for each country. Find the implied public debt level from the public debt-to-GDP ratio $D / Y$.

10. Check the asset market clearing condition (33). Update the interest rate, $r$ using the bisection method.

11. Finally, compute the implied government expenditure, $G$, from (34). 